\title{
O ambiente da investigação em Enfermagem: um relato de experiência
}

\author{
The environment of Nursing research: an experience report \\ El ambiente de la investigación en Enfermería: un relato de experiencia
}

\section{Nauana Nascimento Novais', Luzia Wilma Santana da Silva'}

' Universidade Estadual do Sudoeste da Bahia. Jequié-BA, Brasil.

Submissão: 28/05/2010＜noBreak>Aprovação: 21/08/2010

RESUMO

Trata-se de relato de experiência, de abordagem crítico-reflexivo, e cunho descritivo-compreensivo, sobre a vivência de ser bolsista PIBIC/CNPq da pesquisa multicêntrica "A Dinâmica da família de idosos mais idosos: o convívio e cuidados na quarta idade", no contexto de Jequié-BA, durante o período de vigência da bolsa (Agosto/2008 a Julho/2009). O objetivo é relatar a experiência como bolsista, a fim de estimular outros graduandos a enveredarem pelos caminhos da pesquisa. Os sujeitos dessa pesquisa são o par formado de familiar cuidador principal do idoso de 80 anos e mais de idade e o próprio idoso cuidado. A experiência possibilitou ampliar a visão de mundo, enlaçando contextos, complexidade e intersubjetividade do universo da investigação.

Descritores: Pesquisa em Enfermagem; Família; Idoso de 80 anos ou mais.

\section{ABSTRACT}

This is an experience report, of critical-reflexive approach, and descriptive and comprehensive nature, about the experience of being a stock-student PIBIC/CNPq of a multicentric research titled "The dynamics of the family of older elderly: the living and care in the fourth age", in the context of Jequié-BA, during the term of the scholarship (from August/2008 to July/2009). The objective is to report my experience as an undergraduate student with a scholarship and share it to encourage other students to enter into the paths of research. The subjects of this research are the pair formed by primary family caregivers of the elderly with more than 80 years of age and even the elder to whom the care is given. The experience has broaden the vision of the world, linking context, complexity and intersubjectivity of the investigation universe.

Key words: Nursing Research; Family; Aged, 80 and over.

\section{RESUMEN}

Es un relato de experiencia de abordaje crítico-reflexiva de carácter descriptivo-comprensivo sobre la vivencia de ser becario PIBIC/CNPq en la investigación multicéntrica "La dinámica de la familia de ancianos más viejos: el convivio y el cuidado en la cuarta edad", en el contexto de Jequié-BA, durante la vigencia de la beca (Agosto/2008 a Julio/2009). El objetivo es relatar mi experiencia como becario y compartirla para estimular a otros estudiantes para dirigirse en los caminos de la investigación. Los sujetos de esta investigación son la pareja formada por el familiar cuidador principal del anciano de 80 años o más y el propio anciano cuidado. La experiencia ha permitido ampliar la visión de mundo, enlazando contextos, complejidad y la intersubjetividad del universo de la investigación.

Palabras clave: Investigación en Enfermería; Familia; Anciano de 80 o más Años. 


\section{CONSIDERAÇÕES INICIAIS}

O Programa Institucional de Bolsas de Iniciação Científica - PIBIC destina-se a alunos de graduação, com a finalidade de introduzi-los na pesquisa científica, fornecendo retorno imediato ao bolsista, com vistas à continuidade de sua formação, especialmente na pós-graduação. Desta forma, entre outros objetivos, visa: despertar vocação científica e incentivar talentos potenciais, mediante suas participações em projetos de pesquisa, introduzindo o jovem universitário no domínio do método científico; proporcionar ao bolsista, orientado por pesquisador qualificado, a aprendizagem de técnicas e métodos científicos, bem como estimular o desenvolvimento do pensar cientificamente e da criatividade, decorrentes das condições criadas pelo confronto direto com os problemas de pesquisa, que seja capaz de aumentar a produção científica no cenário nacional ${ }^{(1)}$.

A curiosidade de compreender mais sobre a dinâmica familiar foi o que me impulsionou a participar da seleção de bolsa PIBIC - Conselho Nacional de Desenvolvimento Científico e Tecnológico (CNPq) do projeto intitulado "A Dinâmica da família de idosos mais idosos: o convívio e cuidados na quarta idade". Essa curiosidade foi aguçada no VI semestre da minha graduação na Universidade Estadual do Sudoeste da Bahia (UESB), quando cursei a disciplina optativa Saúde da Família, a qual me possibilitou conhecer como se estruturam as relações intrafamiliares e como a dinâmica familiar interfere no contexto de cada indivíduo, em suas ações e, consequentemente, em sua saúde.

Nesta perspectiva, o mundo da pesquisa se mostrou como um cenário inquietante e desvelador do conhecimento para o ser pesquisador iniciante, fortalecendo sobremaneira a minha formação profissional em Enfermagem, como Bolsista PIBIC-CNPq do referido projeto, no período de Agosto/2008 a Julho/2009.

Antes de ser bolsista dessa pesquisa, tive uma pequena experiência noutra investigação científica como discente voluntária. Porém, naquela oportunidade percebia que minha participação era uma mera instrumentalização técnica, ou seja, apenas executava a coleta de dados sem uma visão crítico-reflexivo-construtiva sobre o meu papel para o despertar à pesquisa. É necessário que todos os envolvidos na pesquisa tenham a oportunidade de se posicionarem, como sujeitos autônomos e ativos neste processo, a fim de que a apropriação do todo seja compartilhada, estabelecendo uma relação de aprendizagem não fragmentadora, nem tampouco colocando os discentes como meros objetos, que, passiva e mecanicamente, respondem às demandas da pesquisa ${ }^{(2)}$.

Assim, a oportunidade da bolsa PIBIC aliada ao trabalho conjunto com a professora orientadora e o grupo da linha de pesquisa "Família e seu Ciclo Vital" promoveram o despertar de uma maturidade para a pesquisa, enquanto sujeito participante de contributos para o enriquecimento e fortalecimento da pesquisa em nosso contexto, por desenvolver o pensar científico, a partir do acompanhamento da trajetória da pesquisa, convivendo, passo-a-passo, com suas fases, potencialidades e dificuldades.
A experiência também conduziu a um olhar mais cônscio do significado de "ser universitário", ultrapassando os muros da universidade e superando o enfoque direcionado apenas à execução dos procedimentos, para viabilizar possibilidades de mudanças na realidade em benefício da comunidade. Assim, o objetivo dessa experiência é relatar a vivência enquanto bolsista PIBIC/CNPq e compartilhar os frutos dessa experiência, a fim de estimular graduandos a se enveredarem pelos caminhos da pesquisa.

\section{MATERIAL E MÉTODOS}

Trata-se de um relato de experiência de abordagem crítico-reflexivo de cunho descritivo-compreensivo sobre a vivência de ser bolsista PIBIC/CNPq da pesquisa multicêntrica intitulada "A Dinâmica da família de idosos mais idosos: o convívio e cuidados na quarta idade", durante o período de vigência da bolsa (Agosto/2008 a Julho/2009), no contexto de Jequié-BA.

Essa pesquisa tem como sede da coordenação geral a Universidade Federal de Santa Catarina (UFSC) e como objetivo conhecer a dinâmica do funcionamento familiar no contexto das relações de cuidado diuturno entre a família e o membro idoso mais idoso (80 anos e mais de idade) dependente de cuidados nos diferentes contextos sócio-culturais de Florianópolis-SC, Jequié-BA, Belém-PA, Palmeira das Missões-RS e a cidade de Porto, em Portugal. É um estudo exploratório-descritivo e diagnóstico-avaliativo, cujos sujeitos são o par formado de familiar cuidador principal do idoso de 80 anos e mais de idade e o próprio idoso cuidado. Os instrumentos para coleta de dados são: Questionário de Perfil da Família Cuidadora - QPFC, WHOQOL-OLD e WHOQOL-Breve da OMS, APGAR familiar e Pentáculo de Bem-Estar.

A amostra da pesquisa é do tipo intencional, selecionada, inicialmente, entre a população definida e circunscrita das famílias cadastradas como usuárias nas Unidades Básicas de Saúde (UBS), em cada contexto de investigação, constituída dos pares supracitados que se voluntariaram ao estudo, assinando o Termo de Consentimento Livre e Esclarecido, segundo aprovação da Pesquisa sob o nº 051/08 da UFSC.

O caminho para desvelar os dados, no contexto do município de Jequié-BA, se deu a priori a partir dos contatos feitos com as enfermeiras/coordenadoras e Agentes Comunitários de Saúde (ACS) das UBS - Unidades de Saúde da Família (USF) e Centros de Saúde (CS) -, a fim de localizar os sujeitos do estudo. Em seguida, foram reproduzidos os instrumentos da pesquisa e organizados em pastas para utilização dos pesquisadores e, posteriormente, realizado treinamento dos discentes e colaboradores da pesquisa para a atuação na investigação. Quando identificada a amostra, a entrada no campo foi realizada através do agendamento, com os ACS, de visitas domiciliares aos sujeitos da pesquisa, para a exposição do projeto, seus objetivos e a importância de sua participação. Caso aceitassem participar, agendava-se novo encontro para iniciar a coleta de dados, e tantos quantos fossem necessários para concluir a coleta das informações. Esse processo ainda encontra-se em desenvolvimento, visto a natureza da pesquisa.

Os dados levantados serão organizados com auxilio da 
estatística descritiva, com apresentação em tabelas e gráficos e analisados por métodos estatísticos pertinentes na exploração das relações entre algumas variáveis do estudo. A discussão será feita comparando os resultados entre si dos cinco contextos sócio-culturais a serem pesquisados, e fundamentando-se nas pesquisas prévias identificadas na revisão de literatura e em bases teórico-conceituais de dinâmica familiar.

\section{RESULTADOS E DISCUSSÃO}

A fim de melhor relatar essa experiência, organizamos este momento do estudo em dois tópicos: "A trajetória bolsista $\mathrm{PIBIC/CNPq}$ ", onde serão relatadas as atividades realizadas durante o período da bolsa, as limitações e as dificuldades; e "A experiência pessoal/profissional", onde serão expressos sentimentos, temores e a percepção em relação à contribuição da pesquisa no crescimento acadêmico para a formação do sujeito coletivo na inserção da investigação científica.

\section{A trajetória bolsista PIBIC/CNPq}

Ao ser aprovada a bolsa, comecei a desvelar o universo da pesquisa, inicialmente, participando de reuniões quinzenais do Grupo de Estudo de Família do Núcleo Interdisciplinar de Estudos e Extensão em Cuidados à Saúde da Família em Convibilidade com Doenças Crônicas (NIEFAM) - Linha de pesquisa: "Família em seu ciclo vital", no qual esta pesquisa está inserida, tendo como eixo de apoio as ações extensionistas desse núcleo, a fim de que as famílias cadastradas no NIEFAM sejam assistidas, mediante suas necessidades. Acredito que esse fato torna a pesquisa ainda mais importante, visto que esta alia ensino-pesquisa-extensão, a fim de proporcionar à comunidade uma melhor qualidade de cuidados à saúde.

Nessas reuniões, além de discutirmos as atividades desenvolvidas pelo grupo e temas que enlaçam o estudo de família na perspectiva sistêmica, também era oportunizado aos participantes do grupo apresentarem seus trabalhos, como por exemplo, teses, dissertações, projetos de pesquisa e trabalhos de conclusão de curso (TCC), entre outros. Isso possibilitou ampliar significativamente os conhecimentos adquiridos na minha graduação, contribuindo com o crescimento acadêmico e dando subsídio às atividades como bolsista.

Também participava de reuniões semanais com os bolsistas de extensão do NIEFAM e a coordenadora da pesquisa, as quais, aliadas à facilidade de acesso à orientadora/coordenadora do projeto, me permitiram tirar dúvidas e compartilhar todo o caminhar do processo da pesquisa, contribuindo para melhorar a compreensão deste processo e, consequentemente, aperfeiçoá-lo.

Concomitantemente a essas reuniões, realizei busca na web off site, Portal de Periódicos CAPES, por Grupos de Estudo de Família nas Universidades Brasileiras e Estrangeiras, a fim de articular parcerias em rede de estudos com o NIEFAM. Além de tentar articulação com estas Universidades, contatamos com Secretarias Municipais - Secretaria Municipal de Saúde (SMS), Secretaria de Desenvolvimento Social (SDS) e Secretaria de Esporte e Lazer (SEL) - e com Projetos de Extensão desenvolvidos por docentes e discentes da UESB, a fim de construir uma rede de referência e contrarreferência para as ações extensionistas do NIEFAM.

Essa estratégia possibilitou enxergar a importância de se trabalhar de maneira articulada, por acreditar que a união de diferentes órgãos sociais pode fortalecer as ações e contribuir eficazmente na tríade ensino-pesquisa-extensão. No entanto, não conseguimos efetivar vínculos com a SDS, o que evidenciou a existência de grandes dificuldades em incorporar o aspecto interdisciplinar ao contexto cotidiano dos diversos segmentos sociais, tornando-se indispensável propor uma maior reflexão sobre o paradigma sistêmico. Entendemos que para reconstruir coletivamente as esferas do pensar e do fazer é preciso ultrapassar as fronteiras que limitam as competências de cada vertente científica, com a ampliação das dimensões do senso crítico necessário para a formação de profissionais comprometidos com a complexidade e abrangência da assistência holística à saúde das pessoas, famílias e coletividades ${ }^{(3)}$.

Já os vínculos com a SEL e a SMS foram efetivados, e tem contribuído com as atividades propostas pelo NIEFAM. A SEL tem disponibilizado quadras poli esportivas, distribuídas pelos bairros do município, onde ocorrem atividades físicas (aeróbicas) com portadores de Diabetes Mellitus e Hipertensão Arterial cadastrados nas UBS desse município. O vínculo com a SMS deu-se através do Grupo de Estudo de Família, ocorridas no auditório desta secretaria, com a participação dos ACS e de Enfermeiras/coordenadoras das UBS do referido município, além dos bolsistas, parceiros, colaboradores e da coordenadora do projeto. Este grupo foi desenvolvido a partir da parceria NIEFAM-SMS, e possibilitou uma maior credibilidade do projeto aos enfermeiros e aos ACS, bem como um maior contato a esses, facilitando a identificação/localização dos sujeitos do estudo e a ocorrência de visitas domiciliares às famílias consideradas de risco, cadastradas nas USB de Jequié-BA e no projeto NIEFAM.

Esse foi um fato importante, já que observei a resistência que muitos deles, em especial os ACS, tiveram em relação à adesão às atividades contributivas ao projeto. Muitos tinham relevante interesse em saber a que, de fato, se propunha o projeto, e apesar de explicarmos seus objetivos - salientando a importância que atribuímos ao fato da pesquisa e extensão andarem juntas, nos comprometendo em acompanhar e dar suporte às necessidades da comunidade - houve desconfianças em relação às verdadeiras intenções do projeto, que, segundo argumentação dos próprios ACS, se deviam a experiências anteriores negativas com outros estudos, os quais, segundo eles, se interessavam em apenas coletar dados e analisá-los, sem dar retorno à comunidade que os forneceu. Isso favorecia ao surgimento de sentimentos negativos, tais como desamparo e frustração, visto que durante o contato com os pesquisadores, a comunidade acaba criando expectativas e laços de confiança. Por isso, havia um temor dos ACS em perder a credibilidade da comunidade, pois são eles o 'elo' entre ela e a Unidade de Saúde, bem como entre nós, pesquisadores.

Considerando o fato dos ACS serem responsáveis por esse 'elo', evidenciamos a importância da estratégia de contatá-los para agendamento das visitas domiciliares na fase de coleta de dados, pois facilitou sobremaneira a localização às residências 
das famílias e a criação de vínculos proximais entre os sujeitos da pesquisa e a pesquisadora. Essa estratégia também aumentou a sensação de segurança física entre os pesquisadores, em locais da comunidade com elevado índice de violência social, pois a companhia dos ACS, durante as primeiras visitas, possibilitou uma maior confiança da comunidade e da equipe pesquisadora, favorecendo o transitar em suas ruas, ruelas e becos. Durante as visitas subseqüentes, realizadas sem a presença dos ACS, o fato de já termos contato prévio aos locais permitiu o deslocamento mais rápido e seguro.

Roese e Lopes ${ }^{(4)}$ relataram sua experiência na fase de coleta de dados, salientando a importância da presença dos ACS nesta fase e os riscos pelos quais estavam expostas no campo de pesquisa, por ser este em locais perigosos. Também em nosso estudo, tivemos situações similares, em que alguns ACS advertiam-nos dos perigos de certas localidades e da necessidade de entrarmos em campo acompanhados e em horários de maior circulação de pessoas. No entanto, tal advertência não pôde ser atendida, visto que nem sempre as visitas podiam ter o acompanhamento dos ACS e muitas vezes tiveram que ser realizadas no período noturno, devido à necessidade de encontrar membros familiares nos domicílios. Assim, o ser pesquisador precisava enfrentar a violência social e o medo, para alcançar o objetivo do seu estudo.

Há de se destacar, também, o quão dispendiosa é a coleta de dados quando realizada em visitas domiciliares, visto que há um elevado custo no deslocamento às casas e um aumento de tempo gasto na execução das entrevistas ${ }^{(4)}$. Daí a constatação de que, se não houvesse financiamento à pesquisa, a locomoção tornar-se-ia um importante obstáculo a ser enfrentado pelos pesquisadores, pois não só durante a coleta de dados necessitamos de transporte, mas também anteriormente, durante a localização dos sujeitos, quando fomos a todas as unidades - algumas delas mais de uma vez - para estabelecer contatos e vínculos com Enfermeiros e ACS, e, posteriormente, no levantamento dos sujeitos que seriam entrevistados.

A experiência no trabalho conjunto, durante a aplicação dos instrumentos da pesquisa, possibilitou aguçar a percepção da necessidade de se compreender as relações humanas em pesquisas que enlaçam pessoas em situação de fragilidade pela doença, visto que inúmeras dificuldades emergiram na aplicação desses: a linguagem complexa destes para compreensão dos sujeitos; a grande quantidade de instrumentos utilizados e repetição em muitas questões que tornaram a pesquisa cansativa para os sujeitos; muito tempo gasto nas entrevistas; as manifestações emotivas dos entrevistados, em especial naquelas famílias com conflitos, que poderiam, por vezes, desviar o foco de investigação; a presença de diversas deficiências senis nos idosos, bem como dificuldades que estes apresentavam em seguir os escores propostos pelas questões. $\mathrm{O}$ que se depreendeu desses instrumentos foi a sua importância, validade e credibilidade na investigação da dinâmica de funcionamento familiar, bem como na avaliação da qualidade de vida e saúde dos subsistemas familiares. No entanto, para a aplicabilidade desses, faz-se necessário domínio do seu conteúdo para evitar vieses na sua aplicação que possam advir de um pesquisador pouco atento aos aspectos relacionais que enovelam as relações parentais no âmbito domiciliar.
Todas essas dificuldades encontradas em campo foram contornadas de maneira eficaz, pois antes mesmo de iniciar a coleta de dados já tínhamos suporte e conhecimento de alguns desses aspectos, devido ao treinamento que foram realizados com os investigadores. Vale salientar que esse treinamento não se traduziu como mero "adestramento" ${ }^{(5)}$ dos envolvidos na pesquisa. Mais que isso, possibilitou aos investigadores desenvolver instrumentação criativa e emancipatória, transformando-os em reais sujeitos da construção e reconstrução do saber, ou seja, sujeitos do processo, com respeito a sua dignidade e autonomia, o que constitui um imperativo ético ${ }^{(2)}$. Freire acrescenta que toda prática educativa demanda a existência de sujeitos, um que, ensinando, aprende, outro que, aprendendo, ensina, daí a qualidade que tem a prática educativa de ser política, de não poder ser neutra(5)

$\mathrm{O}$ fato da bolsa $\mathrm{PIBIC/CNPq}$ proporcionar a participação constante na produção científica e em eventos que divulguem os resultados do estudo é considerado um dos aspectos mais relevantes da pesquisa, já que, através da elaboração de resumos, da confecção de pôsteres, da apresentação pública e da produção de artigos científicos, o graduando é capaz de desenvolver a maturidade frente à ciência, instigando-se a pesquisar e questionar o mundo ao seu redor, o que traduz na formação do seu pensamento crítico da realidade e na possibilidade de compartilhar os frutos da pesquisa com a comunidade científica. Acrescenta-se que a bolsa de pesquisa possibilita aos acadêmicos passar da condição de ouvintes passivos para sujeitos ativos, conscientizando-se da importância de sua inclusão como participantes em todas as atividades acadêmicas ${ }^{(6)}$.

Diante disso, a fim de desenvolver competências auxiliadoras à pesquisa, na qualidade de bolsista, participei de curso sobre "Bases de dados disponíveis na internet, na área de saúde" para subsidiar as pesquisas em bases de dados, que posteriormente auxiliou-me na elaboração de inúmeros trabalhos científicos: um artigo publicado na Revista "Kairós - Gerontologia"; dois trabalhos apresentados na íntegra, um no $60^{\circ} \mathrm{CBEn}$, que recebeu a designação de Honra ao Mérito em $1^{\circ}$ Lugar no prêmio "Vilma de Carvalho", e outro no $61^{\circ} \mathrm{CBEn}$; quatro resumos expandidos, sendo um apresentado no $60^{\circ} \mathrm{CBEn}$, um no II Congresso de Investigação em Enfermagem Ibero-Americano e de Países de Língua Oficial Portuguesa em Coimbra, Portugal, um no XIII Seminário de Iniciação Científica-UESB e um no $61^{\circ} \mathrm{CBEN}$; um Mini-curso desenvolvido no XI Congresso de Pesquisa e Extensão - UESB; e o TCC, que emergiu das experiências adquiridas da bolsa PIBIC CNPq/UESB.

\section{A experiência pessoal/profissional}

Na primeira reunião do Grupo de Estudo sobre Família do NIEFAM, na qual foi apresentada a proposta da pesquisa, esta se revelou em sua dimensão e na responsabilização que exigiria dos seus membros. Assim, foram surgindo, neste momento, sentimentos diversos: receio de não conseguir conciliar o tempo destinado à pesquisa com o das atividades acadêmicas; ansiedade diante desse novo desafio; e preocupações e incertezas referentes à possibilidade de não corresponder às expectativas da orientadora/coordenadora e dos demais integrantes do grupo. No entanto, esses sentimentos foram aos poucos 
trabalhados de forma positiva, no decorrer das reuniões e discussões com a equipe NIEFAM, quando juntos procurávamos soluções para os problemas emergentes, ao passo que as experiências trocadas entre os membros contribuíam para o enriquecimento do grupo como todo.

Quanto à adesão dos sujeitos à pesquisa, não houve muitas dificuldades. Poucas famílias recusaram participar das entrevistas. A maioria dos participantes foram solícitos, alguns bastante calorosos, demonstrando carinho, atenção e satisfação em participar do estudo. Alguns sujeitos agradeciam pela oportunidade de expor sua história de vida, encontrando, no momento da entrevista, a possibilidade de desabafar e de compartilhar suas histórias e angústias com pessoas de fora do seu convívio familiar, que se dispunham a ouvi-los, e que fossem capazes de entender e respeitar seus sentimentos (falas dos sujeitos da pesquisa). Isso conduziu a percepção do ser pesquisador qualitativo em evidenciar situações compreendidas como carência afetiva, em especial naqueles sujeitos que vivenciavam conflitos relacionais intrafamiliares.

A importância do ser pesquisador qualitativo foi evidenciada durante todo o processo de coleta de dados, pois foi necessário deixar a subjetividade do ser exposta, na perspectiva da intersubjetividade quando o ser pesquisador e o ser pesquisado viam-se envolvidos na teia relacional que envolve as relações humanas, e assim, enquanto "pesquisadora" mostrei-me disposta a ajudar, ouvindo-os e procurando compreender o significado dos sentimentos expressos, na forma de angústias manifestas durante o processo da investigação.

No entanto, é importante que o pesquisador não se deixe influenciar ao ponto de perder o foco do estudo e se mantenha, de certa forma, "neutro", para que não haja prejuízo em sua interação com a família( ${ }^{(9)}$. Essa preocupação foi aguçada no período de coleta de dados, pois durante a aplicação dos instrumentos da pesquisa, emergiram diferentes sentimentos e percepções acerca dos sujeitos pesquisados, como também algumas dificuldades pessoal/profissional durante as entrevistas. A primeira dificuldade se fez mostrar no desenvolver habilidades para separar a tênue linha entre ser enfermeiranda-cuidadora e estar enfermeiranda-pesquisadora, pois, ao me deparar com os relatos emocionados dos sujeitos sobre as suas disfunções familiares, tentava de alguma maneira apaziguar o seu sofrimento, o que, por vezes, poderia interferir nos resultados da pesquisa.

Por outro lado, o fato desta pesquisa estar inserida no NIEFAM, onde pesquisa e extensão caminham juntas, torna-se indispensável que este estudo vá além de dados coletados, e que os frutos desta pesquisa contribuam de maneira efetiva e imediata para a melhoria da assistência prestada à comunidade que carece desse cuidado e anseia resultados dos projetos de pesquisa. Desta maneira, durante toda trajetória junto ao projeto, foi possível vivenciar a expressão prática da integração da tríade ensino-pesquisa-extensão. Isso nos leva à compreensão do profissional híbrido dito por Nitschke, ou seja, aquele profissional que não abandona sua formação de base, mas vai, sucessivamente, integrando outros conhecimento ao seu agir ${ }^{(7)}$. Assim, podemos ampliar a nossa visão de mundo, enquanto profissional enfermeiro, que pesquisa e cuida, a fim de melhorar significantemente o atendimento de saúde e construir maneiras de viver saudável, constituindo-se o que possamos chamar de profissional integrativo ${ }^{(8)}$.

Ademais, essa experiência proporcionou uma maior sensibilização das causas sociais, incentivando o despertar do enfermeiro educador e mobilizador do cuidar, no entrelaçamento dos conhecimentos teóricos com a prática assistencial à família que convivem com a cronicidade de seus entes senis. Inúmeras foram as dificuldades encontradas durante esse processo, mas a sua superação foi extremamente gratificante e proporcionou o enriquecimento do processo da graduação, dando-me experiência para ser um profissional crítico-reflexivo, capaz conviver com os obstáculos e contorná-los, a fim de obter melhor êxito no trabalho em cuidar o outro, cuidando-se.

\section{CONSIDERAÇÕES FINAIS}

A trajetória percorrida no período de bolsa PIBIC-CNPq/ UESB oportunizou uma experiência única de crescimento interior e profissional, no aprendizado técnico-científico ao ser sujeito profissional capaz de visualizar nuances, até então despercebidas, a cerca da realidade da saúde vigente em nosso país, mais especificamente no contexto local no qual estamos inseridos, e da necessidade de compreender a família, em suas particularidades, de forma integral. Tal experiência abriu horizontes, possibilitando um olhar mais atencioso e consciencioso do universo da investigação científica. Em outras palavras, oportunidades de caminhar em direção a novos conhecimentos, experiências, descobertas e compartilhar os "frutos" advindos desse caminhar à comunidade científica.

O estudo até aqui desenvolvido tem mostrado a sua relevância para a comunidade científica e especialmente para os sujeitos da pesquisa. Este último merece destaque, uma vez que a referida pesquisa tem como eixo de apoio as ações extensionistas do NIEFAM/UESB, no qual tais famílias poderão ser assistidas, mediante suas necessidades no referido núcleo.

Destaque também se faz para a análise concomitante do estudo, pois, mesmo antes da saturação dos dados, já permitiu tirar algumas conclusões preliminares, demonstrando novas lacunas do conhecimento para outras investigações, a exemplo, o meu TCC de graduação "Qualidade de vida e saúde dos familiares cuidadores de idosos de 80 anos e mais de idade - interferências intrafamiliares". Este surgiu da necessidade de ampliar o olhar para as interferências de cuidados intrafamiliares, uma área de conhecimento ainda pouco explorada, dado evidenciado a partir de revisão de literatura em bases de dados e dos contextos familiares visitados na coleta de dados. Outro aspecto a considerar assenta-se na escassez de estudos fruto de experiências de bolsas de pesquisas que tornassem possível ampliar o diálogo, de maneira a obter subsídios que permitisse um caminhar mais suave e compreensivo frente às dificuldades, às limitações, às conquistas e ao aprendizado, entre outros aspectos.

Numa tentativa de finalização, consideramos que a experiência oportunizou a inquietude de ser pesquisador, pois ao aprender a dar os primeiros passos rumo ao ser crítico-reflexivo-construtivo em direção à ciência e tecnologia em ação, possibilitou ampliar a visão de mundo, enlaçando os contextos, a complexidade e a intersubjetividade do universo da investigação. 


\section{REFERÊNCIAS}

1. Silva EMP. Conselho Nacional de Desenvolvimento Científico e Tecnológico. Normalização do Programa Institucional de Bolsas de Iniciação Científica: Resolução Normativa 019/2001. Brasília (DF); 2001. Disponível em: URL: http://www.udesc.br/arquivos/secao/proppg/pesquisa/resolucao_normativa_019_2001_CNPQ.pdf.

2. Camponogara S, Kirchhof ALC, Gelbcke FL, Magnago TSBS. O espaço do diálogo na pesquisa em enfermagem: relato de experiência sobre a fase de coleta de dados. Texto Contexto Enferm 2007; 16(4): 762-8.

3. Penha AP, Pinheiro LA, Pereira MM, Amorim PT, Cunha GA, Martini JG, et al. Interdisciplinaridade e práticas de iniciação científica: relato de experiência no núcleo interdisciplinar de pesquisa em enfermagem e saúde. In: Anais do XVI Congresso de Iniciação Científica da Universidade Federal do Amazonas; 2007 jul 30-ago 3; Manaus (AM), Brasil. Manaus: EDUA; 2007. v. 282.

4. Roese A, Lopes MJM. A visita domiciliar como instrumento de coleta de dados de pesquisa e vigilância em saúde: relato de experiência. Rev Gaúcha Enferm, Porto Alegre 2004; 25(1): 98-111.

5. Freire P. Pedagogia da autonomia. 4ed. São Paulo (SP): Paz e Terra; 1996.

6. Krahl M, Sobiesiak EF, Poletto DS, Casarin RG, LA Knopf, Carvalho J, et al. Experiência dos acadêmicos de enfermagem em um grupo de pesquisa. Rev Bras Enferm 2009; 62(1): $146-50$.

7. Nitschke RG. Mundo imaginal de ser família saudável: a descoberta dos laços de afeto como caminho numa viagem no quotidiano em tempos pós-modernos [tese]. Florianópolis (SC): UFSC/PEN; 1999.

8. Fernandes JV, Alves C, Nitschke RG. Ser bolsista de extensão: relatando a experiência de promover saúde familiar no cotidiano de uma comunidade de Florianópolis. Rev Bras Enferm 2008; 61(5): 643-6.

9. Mazza MMPR. A visita domiciliária como instrumento de assistência de saúde. Rev. bras. crescimento desenvolv. 1994; 4(2): 60-8. 